\title{
New insights into apolipoprotein A5 in controlling lipoprotein metabolism in obesity and the metabolic syndrome patients
}

\author{
Xin Su', Yi Kong ${ }^{2}$ and Dao-quan Peng ${ }^{1 *}$
}

\begin{abstract}
Apolipoprotein A5 (apoA5) has been identified to play an important role in lipid metabolism, specifically in triglyceride (TG) and TG-rich lipoproteins (TRLs) metabolism. Numerous evidence has demonstrated for an association between apoA5 and the increased risk of obesity and metabolic syndrome, but the mechanism remains to be fully elucidated. Recently, several studies verified that apoA5 could significantly reduce plasma TG level by stimulating lipoprotein lipase (LPL) activity, and the intracellular role of apoA5 has also been proved since apoA5 is associated with cytoplasmic lipid droplets (LDs) and affects intrahepatic TG accumulation. Furthermore, since adipocytes provide the largest storage depot for TG and play a crucial role in the development of obesity, we could infer that apoA5 also acts as a novel regulator to modulate TG storage in adipocytes. In this review, we focus on the association of gene and protein of apoA5 with obesity and metabolic syndrome, and provide new insights into the physiological role of apoA5 in humans, giving a potential therapeutic target for obesity and associated disorders.
\end{abstract}

Keywords: Apolipoprotein A5, Lipoprotein metabolism, Obesity, Metabolic syndrome, Adipocytes

\section{Background}

Obesity, defined as having a body mass index (BMI) of greater than $30 \mathrm{~kg} / \mathrm{m}^{2}$, is associated with a series of health problems which are always grouped together as metabolic syndrome, including type 2 diabetes, dyslipidemia and fatty liver disease [1]. The prevalence of obesity in both developed and developing countries has risen markedly, posing serious risks to future health of humans and leading to a high mortality in the general population all over the world [2]. With the in-depth study, it is now clear that the mechanism of obesity is due to an imbalance of energy intake and consumption [3], and several nutraceuticals and functional food ingredients that are beneficial to vascular health may represent useful compounds that are able to reduce the overall cardiovascular risk induced by dyslipidemia [1]. The hallmark of obesity is excessive accumulation of

\footnotetext{
*Correspondence: pengdq@csu.edu.cn

${ }^{1}$ Department of Cardiovascular Medicine, the Second Xiangya Hospital,

Central South University, Changsha 410011, Hunan, China

Full list of author information is available at the end of the article
}

triglyceride (TG) in adipose tissue [4, 5]. Adipocytes, which are the predominant cell type of this tissue, have been shown to be not only a huge repository of excess energy in form of fat [6] but also a significant source of many metabolites, cytokines and hormones named adipokines under physiological and pathological conditions [7]. In obese state, adipocytes are enlarged and involved in the inordinate regulation of lipid metabolism [8]. The adipocytes isolated from obese mice has an obviously increased in volume, accompanied by various metabolic abnormalities such as cytokine secretion disorders [9] and insulin resistance [10]. In humans, dysfunctional adipocytes have been considered as an important pathophysiological basis of obesity and its related chronic metabolic diseases.

In recent years, a newly discovered apolipoprotein has been proved to be closely related to the occurrence of obesity and metabolic syndrome. Apolipoprotein A5 (apoA5), which was first described in 2001 and considered as a member of the apolipoprotein superfamily, plays an important role in modulating TG metabolism 
[11]. Increasing evidence indicate that apoA5 is a potent regulator of TG despite its low concentration in plasma. Mice lacking APOA5 gene had four times greater plasma TG levels than control group while overexpressing APOA5 gene presented a $66 \%$ decrease in plasma TG levels [11-13]. Furthermore, the variants of APOA5 gene in human of different ethnic groups not only influence plasma TG concentration but also have an association with the prevalence of obesity or metabolic syndrome. Consistently, lower plasma level of apoA5 was found in obese subjects and was inversely correlated with BMI in humans $[14,15]$, suggesting that decreased plasma apoA5 levels may have correlation with pathophysiology of obesity. However, the underlying mechanisms are still ambiguous and cannot fully explained by the controlling effect of apoA5 on plasma TG level. On the other hand, it is noteworthy that apoA5 could also modulate TG storage in hepatocytes [16], indicating a crucial intracellular role of apoA5. Since adipocytes provide the largest storage depot for TG within the lipid droplets (LDs) in humans, studies have also illuminated apoA5 could target to adipocytes and regulate intracellular TG storage $[17,18]$, thus exerting its beneficial effect against obesity. In this review, we focus on the association of APOA5 gene polymorphisms with obesity and the metabolic syndrome, and the potential mechanisms by which apoA 5 may contribute to individual susceptibility to these conditions.

\section{Structural features and tissue distribution of apoA5}

The results of structural and functional studies may help us to understand the basic structure of the apoA5 and its tissue distribution. The human APOA5 gene, exclusively expressed by the liver [19], contains four exons and is located on the long arm of human chromosome 11 adjacent to the APOA1/APOC3/APOA4 gene cluster $[11,19]$. Previous studies revealed that apoA5 protein could be synthesized into plasma by liver at a fairly low level, and the concentration of it ranged from 5.4 to $455.6 \mathrm{ng} / \mathrm{ml}$ in healthy humans [20]. However, recent studies found that a small amount of APOA5 was expressed in human intestine [21], but the physiological functions of this APOA5 gene are still more ambiguous.

The human newly synthesized apoA5 protein consists of 366 amino acids is associated with high-density lipoproteins (HDL), very low density lipoproteins (VLDL) and chylomicrons (CM) [22]. The mature apoA5 protein consists of 343 amino acids and is a highly hydrophobic protein with rich in $\alpha$-helix content [23]. Structure-function studies have indicated that apoA5 contained two independently folded domains, namely a positively charged sequence consisting of the amino acids at positions 186-227, which become a receptor binding domain and could mediate the interaction between apoA5 and heparin or LDL [24]. The C-terminal domain (293-343) of apoA5 protein mediates its binding to lipids [23]. In addition, apoA5 also contains a highly hydrophobic lipid-binding domain (161-181), which binds apoA5 to the surface of LDs $[25,26]$.

\section{Expression regulation of APOA5 gene and protein}

Several nuclear receptors have been confirmed in upregulation of APOA5 gene. Pharmacological studies have shown that APOA5 was a newly discovered target gene of peroxisome proliferator-activated receptor (PPAR) family. Activated PPAR- $\alpha$ could bind to the corresponding site on the promoter of APOA5 gene, thereby increasing the transcriptional expression of APOA5 gene. This progress could induce a significantly reduction of plasma TG content [27, 28]. From this point, since fibrates could specifically activate PPAR- $\alpha$, the mechanism of fibrates in lowering TG and inhibiting dyslipidemia could be explained, at least partly, by up-regulating APOA5 expression [29]. Nevertheless, PPAR- $\gamma$ could not directly interact with apoA5 gene or protein [27]. Researchers have confirmed that PPAR- $\gamma$ was decreased in APOA5 transgenic mice. Using rosiglitazone, a specific agonist of PPAR- $\gamma$, although the gene expression of APOA5 was up-regulated by nearly $70 \%$, the plasma concentration of apoA5 protein was decreased compared to the control group. Therefore, the researchers believed that although both PPAR- $\alpha$ and PPAR- $\gamma$ belong to the PPAR family, their effects on APOA5 expression and function were quite different $[30,31]$.

Secondly, farnesoid X receptor (FXR) and retinoic acid receptor-related orphan receptor (ROR) have also been confirmed to upregulate APOA5 gene expression. Using chenodeoxycholic acid, one of the FXR agonists, the researchers found that plasma concentration of apoA 5 in mice was increased obviously. However, when mice knocked out FXR gene, the plasma content of apoA5 decreased [32]. On the other hand, after transfection of ROR- $\alpha$ into HepG2 cells, researchers found a significant increase of APOA5 gene expression, and among four subtypes of ROR- $\alpha$, only $\alpha 1$ and $\alpha 4$ could transcriptionally up-regulate the expression of APOA5 [33]. Meanwhile, the promoter activity of APOA5 gene was significantly enhanced by transfection of ROR- $\alpha$, and the researchers demonstrated that the specific structure which was in charge of the transcriptional regulation of APOA5 gene expression by ROR- $\alpha$ were three motifs composed of AGGTCA [34].

By contrast, other factors have also been confirmed to down regulate expression of APOA5 gene. T0901317, a specific receptor agonist of liver X receptor (LXR), could significantly decrease the gene and protein expression level of apoA5 in APOA5 transgenic mice. Meanwhile, 
co-transfection of T0901317 with sterol regulatory element-binding protein 1c (SREBP-1c) could also inhibit APOA5 gene promoter activation, whereas when SREBP-1c was silenced, the effect of T0901317 in down-regulating APOA5 gene expression was weakened [35]. These results revealed that LXR reduce the gene expression of APOA5 through the activation of SREBP-1c. Additionally, recent studies have also shown that insulin could lead a substantially lower expression of APOA5 gene and promote the intracellular TG accumulation in a dose-dependent manner in human hepatic cells, and similar results were also obtained in insulin resistant rats [15]. Notably, patients with obesity or diabetes have lower plasma apoA 5 levels compared with the healthy controls, and experimentally-induced hyperinsulinemia also reduced plasma APOA5 levels in healthy men [36]. Furthermore, the researchers used the genomics method and found insulin could activate the phosphatidylinositol 3-kinase (PI3K) signaling pathways and the p70-S6 kinases (p70-S6K) pathways to down-regulated APOA5 gene expression [37]. Interestingly, in contrast to insulin, glucose could promote the transcriptional expression of APOA5 by activating the progress of de-phosphorylation of phosphorylation of upstream stimulatory factors (USFs) [15, 38], and researchers have verified that glucose could promote the binding of USFs (USF1 and USF2) to the functional E-box motif and subsequently facilitate the transcriptional expression of APOA5 gene [39].

\section{APOA5 gene polymorphisms on obesity and the metabolic syndrome \\ APOA5 single nucleotide polymorphisms (SNPs) and obesity}

APOA5 is one of the strongest regulators of plasma TG concentrations and has been linked to obesity. Nevertheless, its mechanisms of action are poorly characterized. Evidence have established an association between the presence of APOA5 gene SNPs and the risk of obesity. As Corella reported in 2007, they examined the interaction between the $-1131 \mathrm{~T}>\mathrm{C}$ and c.56C $>\mathrm{G}(\mathrm{S} 19 \mathrm{~W})$ of APOA5 SNPs and the nutrient intake (total fat, carbohydrate, and protein) in their relation to the BMI and obesity risk in 1073 men and 1207 women participating in the Framingham Offspring Study. By analysis, they found a statistically significant interaction between the $-1131 \mathrm{~T}>\mathrm{C}$ SNP (not the c.56C > G) and total fat intake [40]. In subjects homozygous for the $-1131 \mathrm{~T}$ major allele, BMI increased as total fat intake increased. Conversely, this increase was not present in carriers of the $-1131 \mathrm{C}$ minor allele. Moreover, they found -1131C minor allele carriers had a lower obesity risk in the high fat intake group. The data showed that $-1131 \mathrm{~T}>\mathrm{C}$ SNP could modulate the effect of fat intake on BMI and obesity risk in both men and women [40].

Recently, Sanchez-Moreno have confirmed the interaction between -1131 $\mathrm{T}>\mathrm{C}$ and dietary fat could modulate TG concentrations and anthropometric measures in overweight and obese participants. They recruited 1465 participants from a Spanish population with obesity and found the TG concentration of the patients carried $-1131 \mathrm{~T}>\mathrm{C}$ SNP were higher in carriers of the minor allele. Moreover, they found the participants with homozygous for the $-1131 \mathrm{~T}$ major allele had a positive association between fat intake and obesity, whereas in those carrying the $-1131 \mathrm{C}$ minor allele, higher fat intakes were not associated with higher BMI [41]. Consistent with findings, Horvatovich determined four haplotype-tagging polymorphisms $(-1131 \mathrm{~T}>\mathrm{C}$, IVS3 + 476G > A, c.1259 T > C and c.56C > G) and verified the frequency of major naturally occurring haplotypes of APOA5 in obese children [42]. In the pediatric patients, they demonstrated $-1131 \mathrm{~T}>\mathrm{C}$, IVS3 + G476A and c.1259 T > C variants had an association with elevated TG concentration, both in obese patients and in the controls. The prevalence of the APOA $5 * 2$ haplotype (containing the minor allele of $-1131 \mathrm{~T}>\mathrm{C}$, IVS3 + G476A and c.1259 T > C SNPs together) was $15.5 \%$ in obese children and $5.80 \%$ in the controls, and this haplotype confers susceptibility for development of obesity [43]. By contrast, the APOA $5^{*} 4$ haplotype (with $-1131 \mathrm{C}$ alone) did not show similar associations, while the APOA5*5 haplotype (c.1259 $\mathrm{T}>\mathrm{C}$ alone) could be protective against obesity $[43,44]$.

Interactions between APOA5 and other genes with obesity risk have also been studied. Since apoA5 protein and LPL proteins interact functionally to regulate lipid metabolism, and SNPs for each gene were associated with obesity risk, so evaluating gene combinations may be more effective than single SNP analyses in identifying genetic risk. Nevertheless, insufficient minor allele frequency (MAF) often limits evaluations of potential epistatic relationships. Interestingly, Smith and colleagues examined relationships between LPL m107 and c.56C > G and lipid and anthropometric measures in Caribbean origin Hispanics $(n=1019)$ in the Boston metropolitan area, and they found a higher BMI, waist and hip circumference in carriers with LPL $\mathrm{m} 107$ and the c.56C > G minor allele [45]. Additionally, the risk of extreme obesity (BMI $\geq 40 \mathrm{~kg} / \mathrm{m} 2$ ) was about fourfold increased for minor allele carriers for both SNPs, suggesting that c.56C > G and LPL m107 could interact to modulate obesity [46]. Additionally, Chen et al. also investigated the associations of APOA1 and APOA5 SNPs and their haplotypes with some age-related diseases, as well as with lipids and proteins serum levels in a cohort from a Brazilian Elderly Longitudinal Study (EPIDOSO). They 
found that C-allele of APOA5 SNPs was associated with higher HDL and the GC haplotype, which was composed of the G-allele of APOA1 SNPs and the C-allele of APOA5 SNPs (summarized in Table 1), was significantly associated with obesity, with higher glycated hemoglobin, and fasting glucose [47]. Thus, these results showed that these SNPs were involved in the development of obesity and in alterations of lipids and proteins serum levels in a Brazilian population, and the present findings may also clarify the role of these SNPs and their haplotypes in lipid metabolism.

\section{APOA5 SNPs and metabolic syndrome}

Obesity has been identified to promote the development of metabolic syndrome, so we could speculate APOA5 SNPs may also have potential impact on the metabolic syndrome. Indeed, APOA5 SNPs were reported to be associated with two components of metabolic syndromes: higher TG levels and lower HDL levels.

Table 1 The single polymorphisms of APOA5 gene and the association with obesity and metabolic syndromes

\begin{tabular}{|c|c|c|}
\hline Gene & SNP/position & Association with diseases \\
\hline \multirow[t]{24}{*}{ APOA5 } & \multirow[t]{15}{*}{$-1131 \mathrm{~T}>\mathrm{C}$} & CAD \\
\hline & & Elevated plasma TG \\
\hline & & Elevated LDL-TG \\
\hline & & Decreased HDL-C \\
\hline & & Elevated VLDL-C \\
\hline & & Decreased LDL particle size \\
\hline & & Elevated TG after fasting \\
\hline & & Elevated postprandial TG \\
\hline & & Elevated postprandial VLDL \\
\hline & & Higher dense postprandial LDL \\
\hline & & Elevated postprandial CRP \\
\hline & & Elevated total cholesterol \\
\hline & & Elevated BMI \\
\hline & & Elevated fat intake \\
\hline & & Lower obesity risk \\
\hline & \multirow[t]{2}{*}{ c.1259 T > C } & Elevated plasma TG \\
\hline & & Protective against obesity (alone) \\
\hline & \multirow[t]{3}{*}{$c .56 C>G$} & Higher BMI, waist and hip circumference \\
\hline & & Extreme obesity (carried with LPL m107) \\
\hline & & Decreased HDL \\
\hline & $c .3 A>G$ & Elevated metabolic syndrome risk \\
\hline & $c .553 G>T$ & Elevated metabolic syndrome risk \\
\hline & c.724C > G & Elevated plasma TG \\
\hline & IVS3 $+476 \mathrm{G}>\mathrm{A}$ & Elevated plasma TG \\
\hline
\end{tabular}

CAD coronary artery disease, $T G$ triglyceride, $L D L$ low density lipoprotein, $V L D L$ very low density lipoprotein, $L D L-C$ low density lipoprotein cholesterol, $C R P C$ reactive protein, $L P L$ lipoprotein lipase, $S N P$ single nucleotide polymorphism, $B M I$ body mass index
Early in 2007, most studies about the physiological effects of APOA5 SNPs have focused on $-1131 \mathrm{~T}>\mathrm{C}$ and the results have already demonstrated an independent risk for $-1131 \mathrm{~T}>\mathrm{C}$ SNP in the development of metabolic syndrome. Niculescu and colleagues used a case-control design to determine the association of two APOA5 gene SNPs in a group of urban Romanian subjects with metabolic syndrome. They assayed $-1131 \mathrm{~T}>\mathrm{C}$ SNP for 279 subjects and found a high frequency for $-1131 \mathrm{~T}>\mathrm{C}$ distributed in overweight subjects. The BMI and TG levels were higher in metabolic syndrome patients carried $\mathrm{C}$ allele at the $-1131 \mathrm{~T}>\mathrm{C}$ SNP, however, these $C$ allele homozygotes patients presented lower HDL-C and higher glucose levels compared to subjects with the native gene [48]. Consistent with these findings, Maasz and colleagues studied a total of 421 individuals (211 metabolic syndrome patients and 210 controls) and demonstrated in the group of metabolic syndrome patients, the prevalence of the $-1131 \mathrm{~T}>\mathrm{C}$ SNP was increased compared to the healthy controls. In both groups, the TG levels and the risk of metabolic syndromes were significantly increased approximately threefold of patients with the $-1131 \mathrm{C}$ compared to the subjects with homozygosity for the major $\mathrm{T}$ allele [44, 49]. More recently, Ajjemami investigated the relative contribution of commons APOA5 SNPs and haplotypes to the risk of metabolic syndrome in Moroccan patients. They genotyped APOA5 SNPs in 176 patients and 105 controls and the statistical analysis showed a significant association between $-1131 \mathrm{~T}>\mathrm{C}$ SNP with metabolic syndrome. The patients carried $-1131 \mathrm{~T}>\mathrm{C}$ SNP was associated with increased TG level, waist circumference, fasted glucose and reduced HDL levels. These data confirmed the association of $-1131 \mathrm{~T}>\mathrm{C}$ variants with the predisposition to metabolic syndrome [50].

In addition, several studies have also identified the link between -1131 T > C SNP and the risk of metabolic syndrome in Asian people [51, 52]. In 2008, Hsu used the sample population comprised 615 unrelated subjects, $18.7 \%$ of whom had metabolic syndrome, and found a significantly higher level of TG and a lower level of HDL-C in carriers of the $C$ allele at $-1131 \mathrm{~T}>\mathrm{C}$ SNP than in the non-carriers. Even after adjusting for age, gender, smoking, and regular exercise, the $-1131 \mathrm{~T}>\mathrm{C}$ SNP carriers remained significantly associated with an increased risk of metabolic syndrome [53]. Furthermore, in 2011, a more comprehensive study was conducted by Ong, in terms of both gene coverage and sample size to investigate the associations of APOA5 gene SNPs with the metabolic syndrome in the Hong Kong and Guangzhou Chinese. They genotyped five tagging SNPs in 1330 unrelated subjects from the Hong Kong Cardiovascular Risk Factor Prevalence Study (CRISPS) cohort 
with follow-up after a median interval of 6.4 years, and 1952 subjects from the Guangzhou Biobank Cohort Study-Cardiovascular Disease Sub-cohort (GBCS-CVD). After analysis, the results showed that $-1131 \mathrm{~T}>\mathrm{C}$ SNP was associated with an approximately $50 \%$ higher risk of metabolic syndrome in both two cohorts. These results remained the same after a 6.4-year follow-up period, indicating that the association of $-1131 \mathrm{~T}>\mathrm{C}$ SNP with dyslipidemia could also contribute to an increased susceptibility to metabolic syndrome in the Chinese, as a result of its effect on TG metabolism [54].

Nevertheless, it should be noted that the association of $-1131 \mathrm{~T}>\mathrm{C}$ SNP with metabolic syndrome was not found in German, Austrian and Turkish populations. The ethnic differences in minor allele frequency of $-1131 \mathrm{~T}>\mathrm{C}$ SNP, from $35.3 \%$ in Japanese [55] and $28.3 \%$ in Chinese populations [52] to $12.8 \%$ in a Turkish population [56] and 7.5\% in Caucasian populations [57], may explain this discrepancy, suggesting an ethnic-specific effect of genetic variants in APOA5 on the risk of metabolic syndrome.

Additional data have provided evidence for the association of other functionally relevant APOA5 gene SNPs with metabolic syndrome. A Japanese study examined 44 SNPs at 31 candidate genes and demonstrated that minor alleles at 2 of the APOA5 SNPs examined (c.3A > $\mathrm{G}$ and c.553G $>\mathrm{T}$ ) were significantly associated with increased metabolic syndrome risk [55]. Additionally, Salehi et al. genotyped 116 Iranian children and adolescents with/without metabolic syndrome to explore the association of four INDELs variants of APOA5 gene with risk of metabolic syndrome and its clinical components. They identified a novel insertion polymorphism, c. ${ }^{*} 282-283$ insAG/c. ${ }^{*} 282-283$ insG variant. This SNP showed a significant elevation of TG levels and the risk of metabolic syndrome, revealing that the newly identified SNP might influence the susceptibility of the individuals to metabolic syndrome [58]. More recently, Oliva used pyrosequencing technology to make DNA methylation patterns of three APOA5 regions [promoter, exon 2 and CpG island (CGI) in exon 3] and followed a recruit-by-genotype strategy to study a population composed of 44 individuals with high CVD risk selected as being carriers of at least one APOA5 SNPs $(-1131 \mathrm{~T}>$ $\mathrm{C}$ and/or, c.56C $>\mathrm{G}$ and/or c.724C $>\mathrm{G}$ ) compared against 34 individuals wild-type (WT) for these SNPs. They demonstrated that carriers of APOA5 SNPs had an average of $57.5 \%$ higher circulating TG levels. Among the DNA methylation patterns of APOA5 regions, exon 3 methylation showed a positively relation with TG concentration and with a lipoprotein profile associated with atherogenic dyslipidemia. The highest TG concentrations were found in carriers of at least one SNP and with a methylation in exon 3. In conclusion, CGI methylation in exon 3 of APOA5 gene, in combination with $-1131 \mathrm{~T}>\mathrm{C}$, c. $56 \mathrm{C}>\mathrm{G}$ and c.724C $>\mathrm{G}$ polymorphisms (summarized in Table 1), could play an important role in the predisposition to high circulating TG levels in humans [59]. These results provided examples that combined analysis of SNPs and methylation applied to a larger set of genes would improve our understanding of predisposition to HTG.

\section{The mechanism of apoA5 in modulating obesity and metabolic syndrome}

\section{The extracellular role of apoA5}

As described above, very low concentrations of apoA5 (approximately $0.1 \% \mathrm{w} / \mathrm{w}$ of apoA 1 ) in plasma could unexpectedly has a tremendous and negative impact on plasma TG homeostasis. Knockdown APOA5 gene in mice confers a four-fold increase of plasma TG levels, whereas high-expression of the human APOA5 gene in mice leads to a decrease of TG by approximately $50 \%$ [60]. Moreover, human genetic studies have identified several APOA5 SNPs affected plasma TG levels [61]. Inherited deficiency of the APOA5 gene in humans leaded to severe hypertriglyceridemia. To date, several intensive researches have confirmed the molecular basis of apoA5 on plasma TG levels and the extracellular role of apoA5 seems to be fully elucidated. Indeed, several mechanisms may account for the effect of apoA5 on modulating plasma TG removal.

On one hand, one of the potential mechanisms by which apoA5 regulates plasma TG is the direct or indirect stimulation of LPL-mediated lipolysis of TRLs and their remnants. As we know, lipolysis occurs on the luminal surface of capillaries of skeletal muscle and adipose tissues, and LPL is the rate-limiting enzyme of plasma TG removal [62]. Even though widely distributed in a variety of tissue cells in humans, LPL synthesized in muscle and adipocytes is mainly translocated to capillary endothelial cells. Existed results showed that LPL could attach to the luminal surface of capillary endothelial cells by acting on heparin sulfate proteoglycans (HSPG) to access TRLs particles and hydrolyze them [63]. Using $[3 \mathrm{H}]$-triolein-labeled VLDL-like particles, the researchers found that purified apoA5 protein could stimulate LPL activity in a dose-dependent manner; injection of $[3 \mathrm{H}]$-triolein-labeled VLDL-like particles into APOA5 transgenic mice could significantly accelerate the rate of TRLs clearance of VLDL compared with that in control group, suggesting that apoA5 could increase the effect of LPL in reducing plasma TG level [64]. To observe the role of apoA5 in stimulating the activity of LPL, researchers used APOA5 knockout mice and transfected with LPL and a group of APOA5 transgenic mice lacking LPL, and they found that TG levels was significantly decreased in APOA5 knockout mice with highly active 
LPL, while in the group of APOA5 transgenic mice lack of LPL, TG levels was decreased slightly [65]. These data revealed that the effect of apoA5 in lowering plasma TG level was achieved via the presence of LPL.

Merkel and Kluger have reported that apoA5 could accelerate plasma hydrolysis of TRLs by facilitating interaction with HSPG bound LPL but not with free LPL [66, 67]. Recent data also indicated that apoA5 could serve as a ligand for glycosylphosphatidylinositol high-density lipoprotein binding protein 1 (GPIHBP1), a novel endothelial cell surface protein, which has been postulated to serve as a platform supporting lipolytic activity [68]. Interestingly, Shu et al. found that intravenous injection of recombinant apoA5 protein significantly lowered plasma TG concentrations in APOA5-deficient mice but not in GPIHBP1-knockout mice [16, 69]. Based on these studies, it is conceivable to speculate that apoA5 promotes attachment of TRLs to endothelial cell surface HSPG or GPIHBP1 and that such interactions enhance lipolysis. On the other hand, the hypotriglyceridemic effect of apoA 5 could also be explained by the regulation of TRL clearance mediate by LDL-receptor (LDLR). Numerous of studies have discovered a special positively charged region of apoA5 which was composed of 42 amino acid residues. It has been demonstrated that heparin could bind to members of the LDLR family in this special functional region [65]. Based on the findings that apoA5 can interact with both HSPG and LDLR family members via positively charged regions, and that both
HSPG and LDLR family members function to mediate hepatic endocytosis of TRLs, it is reasonable to speculate that apoA5 could enhance hepatic uptake of these particles. Indeed, Grosskopf reported that removal of chylomicron remnants from plasma was impaired in APOA5-deficient mice, and uptake of remnants in liver-perfusion experiments was weakened [70, 71]. Consistent with these findings, experiments using surface plasmon resonance showed that association of apoA5 with LRP1 resulted in enhanced binding of human chylomicrons to receptor covered sensor chips (Fig. 1). Intriguingly, injection of APOA5 transgenic mice with heparin increased plasma apoA 5 levels by approximately $25 \%$ indicating the existence of a heparin-releasable pool [72].

Overall, these results provide evidence for the possibility that some portion of newly secreted apoA5 protein might bind to HSPG or to receptors on the surface of hepatocytes where it could facilitate lipoprotein binding and uptake.

\section{The intracellular role of apoA5}

Whereas a portion of hepatic-derived apoA5 is secreted into plasma and functions to facilitate LPL-mediated TG hydrolysis, another portion of apoA5 is confirmed to recover intracellularly and is associated with cytosolic LDs [73, 74].

Several results have provided convincing evidence that apoA5 has a role in regulating intracellular TG metabolism. Using transfected doxycycline-inducible McA-RH7777 rat hepatoma cell line, Blade et al. found that apoA5 treatment

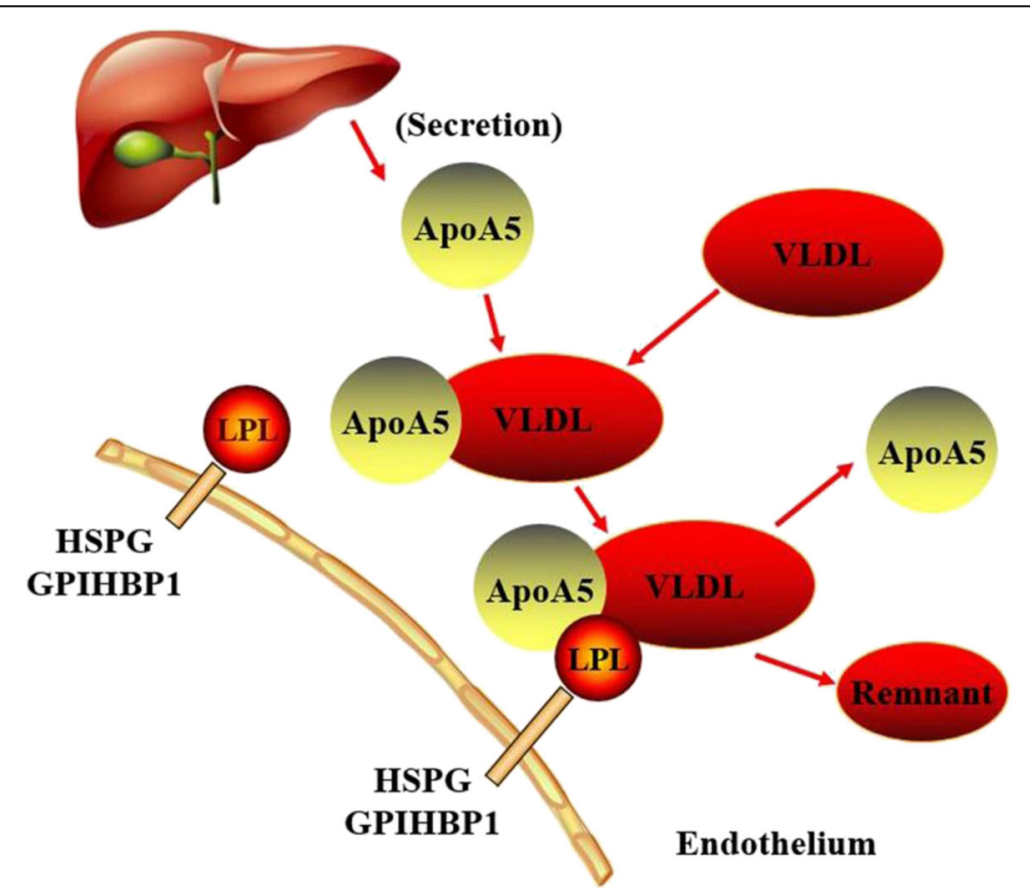

Fig. 1 The extracellular role and the mechanisms of ApoA5. ApoA5 accelerates plasma TG hydrolysis by LPL and can be reused. See text for details 
could inhibit TG secretion, increase intracellular TG concentration and reduce VLDL particle; when stably transfected McA-RH7777 cells were treated with oleic acid, the resulting increased in TG synthesis caused a reduction in apoA5 secretion, which has been considered as a reciprocal increase in cell-associated apoA5. However, no impact on apolipoprotein B (apoB) secretion was observed [75]. These data indicated that reduced TG secretion observed upon induction of apoA5 treatment could be due to the attenuation of second-step particle maturation, essential for the formation of TG-rich VLDL. Additionally, the fact that intrahepatic apoA5 associated with LDs provides evidence that apoA5 can function like many known LD-associated proteins, such as perilipin and adipose differentiation-related protein (ADRP), to help modulate intracellular lipid metabolism. Indeed, studies with APOA5 transgenic mice revealed that apoA5 expression influences intrahepatic TG accumulation [76], and Ress et al. also demonstrated that knockdown of APOA5 in human hepatoma cells resulted in decrease in intracellular TG content (Fig. 2a) [30].

ApoA5 is a potent regulator in TG metabolism in hepatocytes, revealing a crucial intracellular function of apoA5. Since adipocytes are the largest storage depot for energy in the form of TG within the LDs in humans [77], it is reasonable to speculate that apoA5 may also target to adipocytes and regulate intracellular TG storage, providing a potential therapeutic target for obesity. Recently, Zheng and colleagues used pulse-chase experiments and found that apoA5 could be internalized into human mature adipocytes, and about $70 \%$ of the apoA5 internalized during the pulse remained intracellular within a 24-h chase [72]. Pre-incubation with heparin and the receptor-associated protein, both of which could prevent the apoA5 interaction with members of the LDLR gene family, markedly reduced the uptake of apoA5 by 61 and $52 \%$, respectively; meanwhile, using adipocytes with LRP1 knockdown also resulted in a decrease in internalized apoA5 content [72]. Thus, these data revealed that LDLR family members, at least partly, play an important role in inducing apoA5 internalized by adipocytes. In addition, the group also confirmed that the internalized apoA5 was co-localized with LDs in adipocytes by using confocal microscopy and that apoA 5 could significantly decrease intracellular TG storage and the expression of the LDs-associated proteins such as cell death-inducing DNA-fragmentation-factor like effector $\mathrm{C}$ (CIDE-C) and perilipin, leading to a generally smaller $\mathrm{LDs}$ in apoA5-treated cells compared with those in control cells [72, 78]. Furthermore, the adipocytes intervened with apoA5 also presented an obviously increased in lipolysis activity and the gene expression of uncoupling protein 1 (UCP1) [78]. As UCP1 is the brown adipose tissue (BAT)-specific gene and is recognized as the molecular effector of thermogenesis in brown adipocytes [79], these results suggested that decreased TG accumulation in adipocytes induced by apoA 5 may be associated with enhanced lipolysis and energy expenditure.

As demonstrated previously, CIDE-C has been identified as a novel LDs-associated protein in controlling

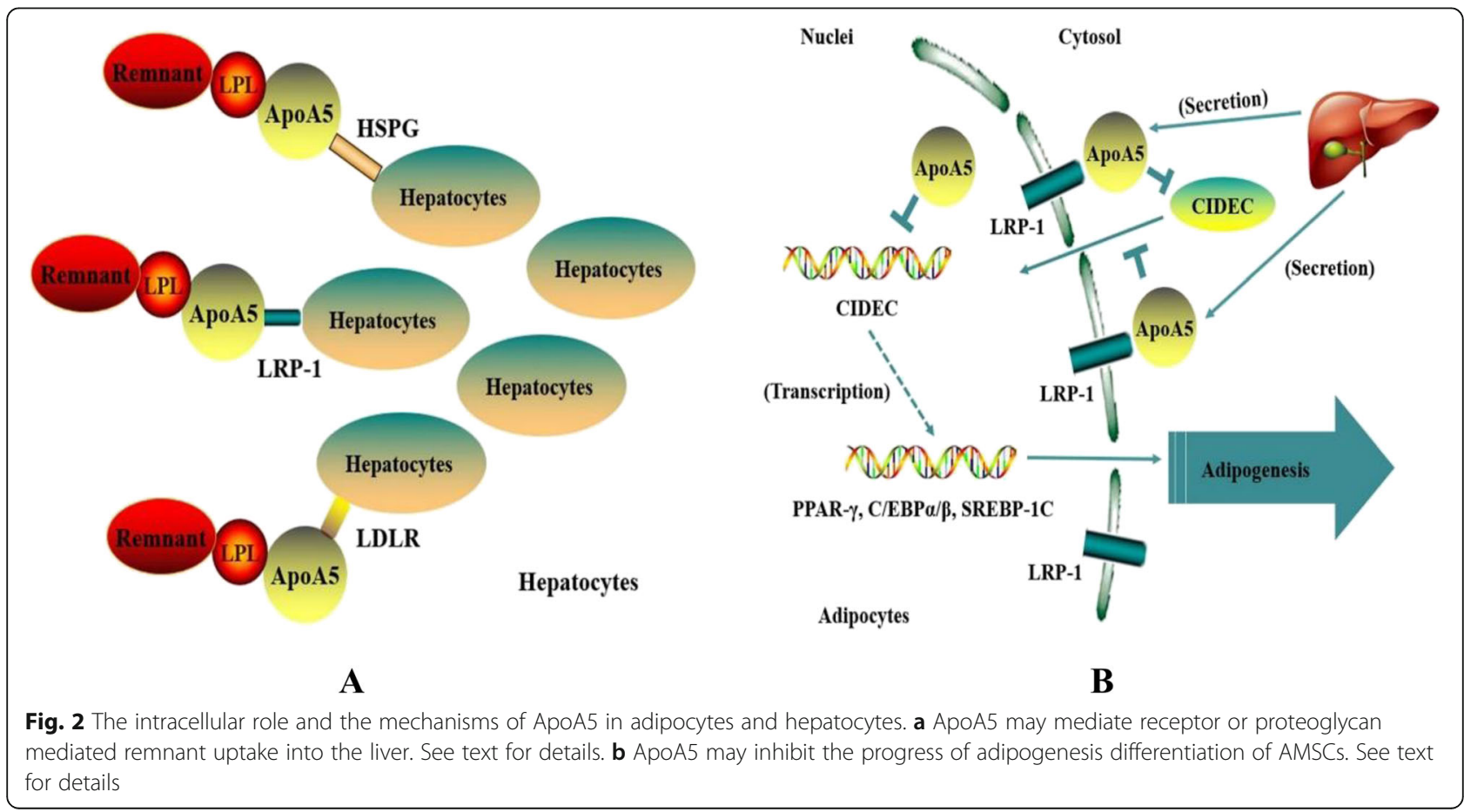


diverse metabolic processes $[80,81]$. To date, researchers focus on the crucial role of CIDE-C in promoting AMSCs differentiation. The latest results showed the level of CIDE-C gene could be significantly up-regulated during the differentiation of AMSCs, and silencing CIDE-C could induce AMSCs losing its ability to differentiate into mature adipocytes [82]. The adipose tissue has abundant adipose-derived mesenchymal stem cells (AMSCs), which can differentiate into mature adipocytes by imbalance between energy intake and expenditure, and the excessive adipogenesis differentiation of AMSCs can lead hyperplasia of adipocytes and promote the pathophysiological development of obesity [83]. Actually, the marked effect of apoA5 on modulating intracellular TG storage and preventing human mature adipocytes from hypertrophy has sparked our interest to investigate whether apoA5 could act as an important regulator for the AMSCs (Fig. 2b). This interesting phenomenon may help us to establish a link of interaction between apoA5 and CIDE-C, but the mechanism of apoA5 in decreasing the expression of CIDE-C is still ambiguous and we need further research.

\section{Conclusions}

Several studies have given evidence for the interaction between APOA5 SNPs and increased risk of obesity and metabolic syndromes, suggesting that the genetic variability of APOA5 plays an important role in modulating lipid metabolism, and the mechanisms of action seems to be clear. Firstly, apoA 5 has been verified to target lipoproteins with HSPG-bound or GPIHBP1-bound LPL, promoting the efficiency of lipoprotein hydrolysis. Secondly, apoA5 facilitates hepatic uptake of TRLs and their remnants through direct interaction with HSPG and meanwhile, apoA5 could also reduce the VLDL-TG production in liver as a result of impaired second-step lipidation of VLDL, leading to a lower TG concentration in plasma. In humans, apoA 5 could be internalized by human adipocytes primarily via binding to LRP1, and the uptake of apoA5 was attenuated in obese adipose tissues and in cultured adipocytes with hypertrophy or insulin resistance. In addition, decreased TG accumulation in human adipocytes induced by ApoA5 intervention may be associated with enhanced lipolysis and energy expenditure, which may result from reduced expression of CIDE-C and perilipin. These findings may provide a greater understanding of the roles of apoA5 in regulating the intracellular TG metabolism of adipocytes.

Furthermore, under hypertrophied and insulin resistant conditions, attenuated endocytosis of apoA 5 by adipocytes may lead to excessive augmentation of TG storage and abnormal metabolism of adipocytes, which promotes the development of obesity. As a novel regulator of lipid storage in adipocytes, apoA5 may serve an important role in whole body energy homeostasis and may be a potential therapeutic target for the treatment of obesity and metabolic syndromes. Besides, as nutraceuticals and functional food ingredients have been verified beneficial to vascular health may represent useful compounds that are able to reduce the overall cardiovascular risk induced by dyslipidemia by acting parallel to medicine or as adjuvants in case of failure or in situations where medicine cannot be used, using apoA5 and nutraceuticals as a combined therapy will become a new treatment.

\section{Abbreviations}

ADRP: Adipose differentiation-related protein; AMSCs: Adipose-derived mesenchymal stem cells; ApoA5: Apolipoprotein A5; ApoB: Apolipoprotein B; BAT: Brown adipose tissue; BMl: Body mass index; CAD: Coronary artery disease; CIDE-C: Cell death-inducing DNA-fragmentation-factor like effector C; CM: Chylomicron; CRISPS: Hong Kong Cardiovascular Risk Factor Prevalence Study; CRP: C-reactive protein; CVD: Cardiovascular disease; FFA: Free fatty acids; FXR: Farnesoid X receptor; GPIHBP1: Glycosylphsphatidylinositolanchored high-density lipoprotein binding protein 1; HDL: High density lipoprotein; HSPG: Heparin sulfate proteoglycans; LDL: Low density lipoprotein; LDLR: LDL-receptor; LDs: Lipid droplets; LPL: Lipoprotein lipase; LXR: Liver X receptor; MAF: Minor allele frequency; P70-S6K: p70-S6 kinases; PI3K: Phosphatidylinositol 3-kinase; PPAR: Peroxisome proliferator-activated receptor; ROR: Retinoic acid receptor-related orphan receptor; SNP: Single nucleotide polymorphism; SREBP-1c: Sterol regulatory element-binding protein 1c; TG: Triglyceride; UCP1: Uncoupling protein 1; USFs: Upstream stimulatory factors; VLDL: Very low density lipoprotein

\section{Funding}

This project was supported by grants from National Natural Science Foundation of China (No.81370393 and No.81670426 to D.P.) and the Graduate Self- Exploration and Innovation Project of Central South University of China (No. $2018 z z t s 923$ to Y.K.).

Authors' contributions

D-QP conceived of the scope of the review and helped draft the manuscript. $\mathrm{XS}$ and YK was involved in the accumulation of the relevant references and drafted the manuscript. All authors read and approved the final manuscript.

Ethics approval and consent to participate

Not applicable.

Consent for publication

Not applicable.

Competing interests

The authors declare that they have no competing interests.

\section{Publisher's Note}

Springer Nature remains neutral with regard to jurisdictional claims in published maps and institutional affiliations.

\section{Author details}

${ }^{1}$ Department of Cardiovascular Medicine, the Second Xiangya Hospital, Central South University, Changsha 410011, Hunan, China. ${ }^{2}$ Department of Dermatology, Hunan Key Laboratory of Medical Epigenomics, the Second Xiangya Hospital, Central South University, Changsha 410011, Hunan, China.

Received: 23 June 2018 Accepted: 20 July 2018

Published online: 27 July 2018

\section{References}

1. Pietro S, Matteo C, Maria M, Pietro AM, Maria LM, Salvatore N, Pasquale P, Pier SS, Roberto P, Marco MC, "Gruppo di Studio Ipertensione, Prevenzione e Riabilitazione", Società Italiana di Cardiologia. Nutraceuticals and dyslipidaemia: beyond the common therapeutics. J Funct Foods. 2014;6:11-32. 
2. Zeng Q, He Y, Dong S, Zhao X, Chen Z, Song Z, Chang G, Yang F, Wang Y. Optimal cut-off values of BMI, waist circumference and waist:height ratio for defining obesity in Chinese adults. Br J Nutr. 2014;112:1735-44.

3. Giusti V, Theytaz F, Di Vetta V, Clarisse M, Suter M, Tappy L. Energy and macronutrient intake after gastric bypass for morbid obesity: a 3-y observational study focused on protein consumption. Am J Clin Nutr. 2016;103:18-24.

4. Schroder $\mathrm{H}$, Fito M, Covas Ml, investigators R. Association of fast food consumption with energy intake, diet quality, body mass index and the risk of obesity in a representative Mediterranean population. Br J Nutr. 2007;98:1274-80,

5. Cedo L, Santos D, Roglans N, Julve J, Pallares V, Rivas-Urbina A, LlorenteCortes V, Laguna JC, Blanco-Vaca F, Escola-Gil JC. Human hepatic lipase overexpression in mice induces hepatic steatosis and obesity through promoting hepatic lipogenesis and white adipose tissue lipolysis and fatty acid uptake. PLoS One. 2017;12:e0189834.

6. Wang C, Wang L, Li W, Yan F, Tian M, Wu C, Qi L, Wang X, Song J, Hou X, Chen L. Irisin has no effect on lipolysis in 3T3-L1 adipocytes or fatty acid metabolism in HepG2 hepatocytes. Endocrine. 2015;49:90-6.

7. Goossens GH. The role of adipose tissue dysfunction in the pathogenesis of obesity-related insulin resistance. Physiol Behav. 2008;94:206-18.

8. Suganami T, Tanaka M, Ogawa Y. Adipose tissue inflammation and ectopic lipid accumulation. Endocr J. 2012;59:849-57.

9. Engin AB. Adipocyte-macrophage cross-talk in obesity. Adv Exp Med Biol. 2017:960:327-43

10. Borgo C, Milan G, Favaretto F, Stasi F, Fabris R, Salizzato V, Cesaro L, Belligoli A, Sanna M, Foletto M, et al. CK2 modulates adipocyte insulin-signaling and is up-regulated in human obesity. Sci Rep. 2017;7:17569.

11. Pennacchio LA, Olivier M, Hubacek JA, Cohen JC, Cox DR, Fruchart JC, Krauss RM, Rubin EM. An apolipoprotein influencing triglycerides in humans and mice revealed by comparative sequencing. Science. 2001;294:169-73.

12. van der Vliet HN, Sammels MG, Leegwater AC, Levels JH, Reitsma PH, Boers W, Chamuleau RA. Apolipoprotein A-V: a novel apolipoprotein associated with an early phase of liver regeneration. J Biol Chem. 2001;276:44512-20.

13. Merkel M, Loeffler B, Kluger M, Fabig N, Geppert G, Pennacchio LA, Laatsch A, Heeren J. Apolipoprotein AV accelerates plasma hydrolysis of triglyceriderich lipoproteins by interaction with proteoglycan-bound lipoprotein lipase. J Biol Chem. 2005;280:21553-60.

14. Zhao SP, Hu S, Li J, Hu M, Liu Q, Wu LJ, Zhang T. Association of human serum apolipoprotein A5 with lipid profiles affected by gender. Clin Chim Acta. 2007;376:68-71

15. Huang XS, Zhao SP, Hu M, Bai L, Zhang Q, Zhao W. Decreased apolipoprotein A5 is implicated in insulin resistance-related hypertriglyceridemia in obesity. Atherosclerosis. 2010;210:563-8.

16. Shu X, Nelbach L, Ryan RO, Forte TM. Apolipoprotein A-V associates with intrahepatic lipid droplets and influences triglyceride accumulation. Biochim Biophys Acta. 2010;1801:605-8.

17. Subash-Babu P, Alshatwi AA. Aloe-emodin inhibits adipocyte differentiation and maturation during in vitro human mesenchymal stem cell adipogenesis. J Biochem Mol Toxicol. 2012;26:291-300.

18. Tang QQ, Lane MD. Adipogenesis: from stem cell to adipocyte. Annu Rev Biochem. 2012;81:715-36.

19. van der Vliet HN, Schaap FG, Levels JH, Ottenhoff R, Looije N, Wesseling JG, Groen AK, Chamuleau RA. Adenoviral overexpression of apolipoprotein A-V reduces serum levels of triglycerides and cholesterol in mice. Biochem Biophys Res Commun. 2002;295:1156-9.

20. Seydel C. Genome research. Possible new heart disease risk factor. Science. 2001:294:33.

21. Guardiola M, Alvaro A, Vallve JC, Rosales R, Sola R, Girona J, Serra N, Duran $P$, Esteve E, Masana L, Ribalta J. APOA5 gene expression in the human intestinal tissue and its response to in vitro exposure to fatty acid and fibrate. Nutr Metab Cardiovasc Dis. 2012;22:756-62.

22. Zhang LS, Sato H, Yang Q, Ryan RO, Wang DQ, Howles PN, Tso P. Apolipoprotein $\mathrm{A}-\mathrm{V}$ is present in bile and its secretion increases with lipid absorption in SpragueDawley rats. Am J Physiol Gastrointest Liver Physiol. 2015;309:G918-25.

23. Weinberg RB, Cook VR, Beckstead JA, Martin DD, Gallagher JW, Shelness GS, Ryan RO. Structure and interfacial properties of human apolipoprotein A-V. Biol Chem. 2003;278:34438-44.

24. Lookene A, Beckstead JA, Nilsson S, Olivecrona G, Ryan RO. Apolipoprotein A-V-heparin interactions: implications for plasma lipoprotein metabolism. J Biol Chem. 2005;280:25383-7.

25. Nilsson SK, Heeren J, Olivecrona G, Merkel M. Apolipoprotein A-V; a potent triglyceride reducer. Atherosclerosis. 2011;219:15-21.
26. Sheng L, Liu Y, Jiang L, Chen Z, Zhou Y, Cho KW, Rui L. Hepatic SH2B1 and SH2B2 regulate liver lipid metabolism and VLDL secretion in mice. PLoS One. 2013;8:e83269.

27. Qiu L, Ye H, Chen L, Hong Y, Zhong F, Zhang T. Red clover extract ameliorates dyslipidemia in streptozotocin-induced diabetic C57BL/6 mice by activating hepatic PPARalpha. Phytother Res. 2012;26:860-4.

28. Gonzalez Mdel C, Corton JC, Acero N, Munoz-Mingarro D, Quiros Y, AlvarezMillan JJ, Herrera E, Bocos C. Peroxisome proliferator-activated receptoralpha agonists differentially regulate inhibitor of DNA binding expression in rodents and human cells. PPAR Res. 2012;2012:483536.

29. Okopien B, Buldak L, Boldys A. Fibrates in the management of atherogenic dyslipidemia. Expert Rev Cardiovasc Ther. 2017;15:913-21.

30. Ress C, Moschen AR, Sausgruber N, Tschoner A, Graziadei I, Weiss H, Schgoer W, Ebenbichler CF, Konrad RJ, Patsch JR, et al. The role of apolipoprotein A5 in non-alcoholic fatty liver disease. Gut. 2011;60:985-91.

31. Ramakrishnan L, Sachdev HS, Sharma M, Abraham R, Prakash S, Gupta D, Singh Y, Bhaskar S, Sinha S, Chandak GR, et al. Relationship of APOA5, PPARgamma and $\mathrm{HL}$ gene variants with serial changes in childhood body mass index and coronary artery disease risk factors in young adulthood. Lipids Health Dis. 2011;10:68.

32. Prieur $\mathrm{X}$, Coste $\mathrm{H}$, Rodriguez JC. The human apolipoprotein AV gene is regulated by peroxisome proliferator-activated receptor-alpha and contains a novel farnesoid X-activated receptor response element. J Biol Chem. 2003;278:25468-80.

33. Genoux A, Dehondt H, Helleboid-Chapman A, Duhem C, Hum DW, Martin G, Pennacchio LA, Staels B, Fruchart-Najib J, Fruchart JC. Transcriptional regulation of apolipoprotein $\mathrm{A} 5$ gene expression by the nuclear receptor RORalpha. Arterioscler Thromb Vasc Biol. 2005;25:1186-92.

34. Lind U, Nilsson T, McPheat J, Stromstedt PE, Bamberg K, Balendran C, Kang D. Identification of the human ApoAV gene as a novel RORalpha target gene. Biochem Biophys Res Commun. 2005;330:233-41.

35. Jakel H, Nowak M, Moitrot E, Dehondt H, Hum DW, Pennacchio LA, Fruchart-Najib J, Fruchart JC. The liver X receptor ligand T0901317 downregulates APOA5 gene expression through activation of SREBP-1C. J Biol Chem. 2004;279:45462-9.

36. Pamir N, McMillen TS, Li YI, Lai CM, Wong H, LeBoeuf RC. Overexpression of apolipoprotein $\mathrm{A} 5$ in mice is not protective against body weight gain and aberrant glucose homeostasis. Metabolism. 2009;58:560-7.

37. Sharma D, Garg S, Mehndiratta M, Madhu SV, Puri D. Relationship of serum apolipoprotein A-V levels, oxidative stress and inflammatory biomarkers with hypertriglyceridemia in type 2 diabetes mellitus. Int J Endocrinol Metab. 2017;15:e44805.

38. Laurila PP, Naukkarinen J, Kristiansson K, Ripatti S, Kauttu T, Silander K, Salomaa V, Perola M, Karhunen PJ, Barter PJ, et al. Genetic association and interaction analysis of USF1 and APOA5 on lipid levels and atherosclerosis. Arterioscler Thromb Vasc Biol. 2010;30:346-52.

39. Singmann P, Baumert J, Herder C, Meisinger C, Holzapfel C, Klopp N, Wichmann HE, Klingenspor M, Rathmann W, Illig T, Grallert H. Gene-gene interaction between APOA5 and USF1: two candidate genes for the metabolic syndrome. Obes Facts. 2009;2:235-42.

40. Corella D, Lai CQ, Demissie S, Cupples LA, Manning AK, Tucker KL, Ordovas JM. APOA5 gene variation modulates the effects of dietary fat intake on body mass index and obesity risk in the Framingham Heart Study. J Mol Med (Berl). 2007:85:119-28.

41. Sanchez-Moreno C, Ordovas JM, Smith CE, Baraza JC, Lee YC, Garaulet M. APOA5 gene variation interacts with dietary fat intake to modulate obesity and circulating triglycerides in a Mediterranean population. J Nutr. 2011;141:380-5.

42. Kisfali P, Mohas M, Maasz A, Polgar N, Hadarits F, Marko L, Brasnyo P, Horvatovich K, Oroszlan T, Bagosi Z, et al. Haplotype analysis of the apolipoprotein A5 gene in patients with the metabolic syndrome. Nutr Metab Cardiovasc Dis. 2010;20:505-11.

43. Kisfali P, Mohas M, Maasz A, Hadarits F, Marko L, Horvatovich K, Oroszlan T, Bagosi Z, Bujtor Z, Gasztonyi B, et al. Apolipoprotein A5 IVS3+476A allelic variant associates with increased trigliceride levels and confers risk for development of metabolic syndrome in Hungarians. Circ J. 2008;72:40-3.

44. Maasz A, Kisfali P, Jaromi L, Horvatovich K, Szolnoki Z, Csongei V, Safrany E, Sipeky C, Hadarits F, Melegh B. Apolipoprotein A5 gene IVS3+G476A allelic variant confers susceptibility for development of ischemic stroke. Circ J. 2008;72:1065-70.

45. Smith CE, Tucker KL, Lai CQ, Parnell LD, Lee YC, Ordovas JM. Apolipoprotein $\mathrm{A} 5$ and lipoprotein lipase interact to modulate anthropometric measures in Hispanics of Caribbean origin. Obesity (Silver Spring). 2010;18:327-32. 
46. Ariza MJ, Sanchez-Chaparro MA, Baron FJ, Hornos AM, Calvo-Bonacho E, Rioja J, Valdivielso P, Gelpi JA, Gonzalez-Santos P. Additive effects of LPL APOA5 and APOE variant combinations on triglyceride levels and hypertriglyceridemia: results of the ICARIA genetic sub-study. BMC Med Genet. 2010;11:66

47. Chen ES, Furuya TK, Mazzotti DR, Ota VK, Cendoroglo MS, Ramos LR, Araujo LQ, Burbano RR, de Arruda Cardoso Smith M. APOA1/A5 variants and haplotypes as a risk factor for obesity and better lipid profiles in a Brazilian Elderly Cohort. Lipids. 2010;45:511-7.

48. Niculescu LS, Fruchart-Najib J, Fruchart JC, Sima A. Apolipoprotein A-V gene polymorphisms in subjects with metabolic syndrome. Clin Chem Lab Med. 2007:45:1133-9.

49. Maasz A, Kisfali P, Horvatovich K, Mohas M, Marko L, Csongei V, Farago B, Jaromi L, Magyari L, Safrany E, et al. Apolipoprotein A5 T-1131C variant confers risk for metabolic syndrome. Pathol Oncol Res. 2007;13:243-7.

50. Ajjemami M, Ouatou S, Charoute H, Fakiri M, Rhaissi H, Benrahma H, Rouba $\mathrm{H}$, Barakat A. Haplotype analysis of the apolipoprotein A5 gene in Moroccan patients with the metabolic syndrome. J Diabetes Metab Disord. 2015;14:29.

51. Jang Y, Kim JY, Kim OY, Lee JE, Cho H, Ordovas JM, Lee JH. The -1131T-->C polymorphism in the apolipoprotein $\mathrm{A} 5$ gene is associated with postprandial hypertriacylglycerolemia; elevated small, dense LDL concentrations; and oxidative stress in nonobese Korean men. Am J Clin Nutr. 2004:80:832-40

52. Bi N, Yan SK, Li GP, Yin ZN, Chen BS. A single nucleotide polymorphism $-1131 \mathrm{~T}>\mathrm{C}$ in the apolipoprotein A5 gene is associated with an increased risk of coronary artery disease and alters triglyceride metabolism in Chinese. Mol Genet Metab. 2004;83:280-6.

53. Hsu LA, Ko YL, Chang CJ, Teng MS, Wu S, Hu CF. Apolipoprotein A5 gene $-1131 \mathrm{~T} / \mathrm{C}$ polymorphism is associated with the risk of metabolic syndrome in ethnic Chinese in Taiwan. Clin Chem Lab Med. 2008:46:1714-9.

54. Ong KL, Jiang CQ, Liu B, Jin YL, Tso AW, Tam S, Wong KS, Tomlinson B, Cheung BM, Lin JM, et al. Association of a genetic variant in the apolipoprotein A5 gene with the metabolic syndrome in Chinese. Clin Endocrinol. 2011:74:206-13.

55. Yamasaki M, Mutombo PB, Iwamoto M, Nogi A, Hashimoto M, Nabika T, Shiwaku K. The interaction of apolipoprotein A5 gene promoter region T1131C polymorphism (rs12286037) and lifestyle modification on plasma triglyceride levels in Japanese. Nutr Res Pract. 2015;9:379-84.

56. Can Demirdogen B, Sahin E, Turkanoglu Ozcelik A, Bek S, Demirkaya S, Adali O. Apolipoprotein A5 polymorphisms in Turkish population: association with serum lipid profile and risk of ischemic stroke. Mol Biol Rep. 2012;39:10459-68.

57. Sun $Y$, Zhou RB, Chen DM. APOA5 - $1131 \mathrm{~T}>C$ and APOC3 -455T>C polymorphisms are associated with an increased risk of coronary heart disease. Genet Mol Res. 2015;14:18218-28.

58. Salehi S, Emadi-Baygi M, Rezaei M, Kelishadi R, Nikpour P. Identification of a new single-nucleotide polymorphism within the apolipoprotein A5 gene, which is associated with metabolic syndrome. Adv Biomed Res. 2017:6:24

59. Oliva I, Guardiola M, Vallve JC, Ibarretxe D, Plana N, Masana L, Monk D, Ribalta J. APOA5 genetic and epigenetic variability jointly regulate circulating triacylglycerol levels. Clin Sci (Lond). 2016;130:2053-9.

60. Forte TM, Ryan RO. Apolipoprotein A5: extracellular and intracellular roles in triglyceride metabolism. Curr Drug Targets. 2015;16:1274-80.

61. Forte TM, Sharma V, Ryan RO. Apolipoprotein A-V gene therapy for disease prevention / treatment: a critical analysis. J Biomed Res. 2016;30:88-93.

62. Ghorbani A, Abedinzade M. Comparison of in vitro and in situ methods for studying lipolysis. ISRN Endocrinol. 2013;2013:205385.

63. Essalmani R, Susan-Resiga D, Chamberland A, Asselin MC, Canuel M, Constam D, Creemers JW, Day R, Gauthier D, Prat A, Seidah NG. Furin is the primary in vivo convertase of angiopoietin-like 3 and endothelial lipase in hepatocytes. J Biol Chem. 2013;288:26410-8.

64. Li Y, He PP, Zhang DW, Zheng XL, Cayabyab FS, Yin WD, Tang CK. Lipoprotein lipase: from gene to atherosclerosis. Atherosclerosis. 2014;237:597-608.

65. Hubacek JA. Apolipoprotein A5 fifteen years anniversary: lessons from genetic epidemiology. Gene. 2016;592:193-9.

66. Kluger M, Heeren J, Merkel M. Apoprotein A-V: an important regulator of triglyceride metabolism. J Inherit Metab Dis. 2008;31:281-8.

67. Merkel M, Heeren J. Give me A5 for lipoprotein hydrolysis! J Clin Invest. 2005:115:2694-6.

68. Rabacchi C, D'Addato S, Palmisano S, Lucchi T, Bertolini S, Calandra S, Tarugi $P$. Clinical and genetic features of 3 patients with familial chylomicronemia due to mutations in GPIHBP1 gene. J Clin Lipidol. 2016;10:915-921 e914.
69. Shu X, Nelbach L, Weinstein MM, Burgess BL, Beckstead JA, Young SG, Ryan $\mathrm{RO}$, Forte TM. Intravenous injection of apolipoprotein A-V reconstituted high-density lipoprotein decreases hypertriglyceridemia in apoav-/- mice and requires glycosylphosphatidylinositol-anchored high-density lipoprotein-binding protein 1. Arterioscler Thromb Vasc Biol. 2010;30:2504-9.

70. Grosskopf I, Baroukh N, Lee SJ, Kamari Y, Harats D, Rubin EM, Pennacchio LA, Cooper AD. Apolipoprotein A-V deficiency results in marked hypertriglyceridemia attributable to decreased lipolysis of triglyceride-rich lipoproteins and removal of their remnants. Arterioscler Thromb Vasc Biol. 2005;25:2573-9.

71. Grosskopf I, Shaish A, Afek A, Shemesh S, Harats D, Kamari Y. Apolipoprotein $A-V$ modulates multiple atherogenic mechanisms in a mouse model of disturbed clearance of triglyceride-rich lipoproteins. Atherosclerosis. 2012; 224:75-83.

72. Zheng XY, Zhao SP, Yu BL, Wu CL, Liu L. Apolipoprotein A5 internalized by human adipocytes modulates cellular triglyceride content. Biol Chem. 2012; 393:161-7.

73. Puri V, Czech MP. Lipid droplets: FSP27 knockout enhances their sizzle. J Clin Invest. 2008;118:2693-6.

74. Yoshino Y, Okada T, Abe Y, Odaka M, Kuromori Y, Yonezawa R, Iwata F, Mugishima $\mathrm{H}$. Apolipoprotein A-V level may contribute to the development of obesity-associated dyslipidemia. Obes Res Clin Pract. 2013;7:e415-9.

75. Blade AM, Fabritius MA, Hou L, Weinberg RB, Shelness GS. Biogenesis of apolipoprotein $\mathrm{A}-\mathrm{V}$ and its impact on VLDL triglyceride secretion. J Lipid Res. 2011;52:237-44.

76. Wu CL, Zhao SP, Yu BL. Intracellular role of exchangeable apolipoproteins in energy homeostasis, obesity and non-alcoholic fatty liver disease. Biol Rev Camb Philos Soc. 2015;90:367-76.

77. Li R, Chen LZ, Zhao W, Zhao SP, Huang XS. Metformin ameliorates obesityassociated hypertriglyceridemia in mice partly through the apolipoprotein A5 pathway. Biochem Biophys Res Commun. 2016;478:1173-8.

78. Zheng XY, Yu BL, Xie YF, Zhao SP, Wu CL. Apolipoprotein A5 regulates intracellular triglyceride metabolism in adipocytes. Mol Med Rep. 2017;16:6771-9.

79. Bond LM, Ntambi JM. UCP1 deficiency increases adipose tissue monounsaturated fatty acid synthesis and trafficking to the liver. J Lipid Res. 2017:59:224-36.

80. Tan X, Cao Z, Li M, Xu E, Wang J, Xiao Y. TNF-alpha downregulates CIDEC via MEK/ERK pathway in human adipocytes. Obesity (Silver Spring). 2016;24:1070-80.

81. Xu L, Xia X, Arshad M, Zhou L. Gene expression profile in the fat tissue of Fsp27 deficient mice. Genom Data. 2015;5:326-8.

82. Xu L, Zhou L, Li P. CIDE proteins and lipid metabolism. Arterioscler Thromb Vasc Biol. 2012;32:1094-8.

83. Moreno-Navarrete JM, Ortega F, Serrano M, Rodriguez-Hermosa Jl, Ricart W, Mingrone G, Fernandez-Real JM. CIDEC/FSP27 and PLIN1 gene expression run in parallel to mitochondrial genes in human adipose tissue, both increasing after weight loss. Int J Obes. 2014;38:865-72.

Ready to submit your research? Choose BMC and benefit from:

- fast, convenient online submission

- thorough peer review by experienced researchers in your field

- rapid publication on acceptance

- support for research data, including large and complex data types

- gold Open Access which fosters wider collaboration and increased citations

- maximum visibility for your research: over $100 \mathrm{M}$ website views per year

At $\mathrm{BMC}$, research is always in progress.

Learn more biomedcentral.com/submission 